\section{Plant Mass and Yield of Broccoli as Affected by Soil Moisture}

\author{
Bodo Gutezeit \\ Institute of Vegetable and Ornamental Crops Großbeeren and Erfurt, Theodor \\ Echtermeyer Weg D-14979, Großbeeren, Germany
}

Additional index words. head mass, irrigation, Brassica oleracea L. var. italica

\begin{abstract}
The effect of water supply on total mass and yield of broccoli (Brassica oleracea L. var. italica, 'Emperor') was examined in an experiment carried out in a microplot field installation on three soil types: Gleyic Cambisol (sand) and Eutric Fluvisol (flood-plain loam) in spring and fall and on a Haplic Phaeosem (loessal loam) in fall. Soil moisture levels were established by irrigation under the following replacement protocols: $14 \mathrm{~mm}$ whenever the limit of $75 \%$ vol of the available soil water (ASW), 14 and $28 \mathrm{~mm}$ whenever the limit of $55 \%$ vol of ASW, and 14, 28, and $42 \mathrm{~mm}$ whenever the limit of $35 \%$ vol of ASW were reached. The highest total plant mass was achieved by irrigation at $75 \%$ vol of ASW on the sandy soil in spring cultivation, and at $55 \%$ vol of ASW (in doses of $28 \mathrm{~mm}$ ) on the flood-plain loam in fall cultivation. The highest marketable yield (head mass) was obtained on the sandy soil at $55 \%$ vol of ASW (in doses of $14 \mathrm{~mm}$ ) for both spring and fall production. The total plant mass and head mass was only significantly affected by reduced soil moisture at $35 \%$ vol of ASW in spring. At 75\% vol of ASW, irrigation with $14 \mathrm{~mm}$ always resulted in reduced headmass. In fall, yield was not affected by soil moisture depletion or soil type. For the production of broccoli, it is recommended that irrigation be started when soil moisture falls below $55 \%$ vol of ASW, followed by a water application rates of either 14 or $28 \mathrm{~mm}$.
\end{abstract}

The aim of irrigation management is to control soil water for optimal crop yield and quality while conserving water. Many papers have been published on various aspects of the adequacy of available soil moisture levels in the root zone, and of water relations in soil and plants (Alvino et al., 1990; Cavazza, 1988; Dasberg, 1999; Hsiao, 1990). The amount of water within the plant is small compared with the amount of transpired water, and as a consequence, water uptake from the soil via the roots is very high. Horticulturists and agronomists are always concerned with the availability of soil moisture in the root zone, which should preferably be at or near field capacity so that plant growth is not adversely affected (Sharda and Singh, 1993). According to Wiebe (1981), the highest plant dry matter yield of the total plant is obtained at a soil water potential of 0 $\mathrm{Pa}$, provided the oxygen supply to the roots is maintained. He concluded that the factors that influence yield in different soil types at the same water potential are the 1) oxygen content of the soil, 2) oxygen transport to the roots, 3) water transport to the roots in unsaturated soils, and 4) evapotranspiration.

The extraction of water by roots and evaporation losses progressively reduce the moisture content of the soil to less than field capacity. If not replenished, soil water levels may ultimately reach the wilting point for plant growth. Therefore, predicting the water content in the root zone can be a means of helping the farmer decide when, and how much to irrigate.

Soil water content is normally not measured by growers because of time and cost.

Received for publication 22 Apr. 2004. Accepted for publication 26 Sept. 2004.

${ }^{1}$ To whom reprint requests should be addressed; e-mail Gutezeit@igzev.de.

${ }^{\mathrm{y}}$ In $\mathrm{g} \cdot \mathrm{cm}^{-3}$.

xPercent by volume of soil.

${ }^{\mathrm{z}} \mathrm{ASW}=$ available soil water.

${ }^{y}$ Amount applied $14 \mathrm{~mm}$ twice.

${ }^{x}$ Amount applied $14 \mathrm{~mm}$ three times.
However, the initial moisture status of the soil is very difficult to determine for a model applied on a large scale. Furthermore, investigations have indicated that the amount of water applied by growers is far in excess of the actual amount required (Buchleiter and Unruh, 1993). Rana and Katerji (1998) also demonstrated that when crops are under water stress, the key parameter to be evaluated is the plant water status of the canopy.

Many models exist for irrigation scheduling that use physiological, meteorological, or soil parameters. Most of the models perform well in regions where climatic conditions are similar to those of the region for which the model was originally developed. Elsewhere, however, the models tend to either over- or underpredict the potential evapotranspiration. Broccoli (Brassica oleracea L. var. italica) is an important field-grown vegetable (in Germany broccoli production area increased from 680 ha in 1992 to 2200 ha in 2000) (Behr, 2001) and water deficits in any growth stage will decrease optimum growth and head quality. The objective of this experiment was to determine the effects of different levels of available soil water and various water replacement by irrigation strategies on the total mass and marketable yield of broccoli, in order to estimate critical soil moisture levels for irrigation in different soil types and improve the accuracy of current management models.

\section{Materials and Methods}

The experiment was conducted with spring and fall plantings of broccoli on three soil types (on loam in fall only) in a box frame plot installation at the experimental station of the Institute of Vegetable and Ornamental Crops in Grossbeeren, Germany. The plot size was $2 \times 2 \times 0.75 \mathrm{~m}$ (depth). The plots were buried in the ground and constructed with concrete

Table 1. Physical and chemical parameters of the soils.

\begin{tabular}{lccc}
\hline Property & $\begin{array}{c}\text { Sand } \\
\text { (Gleyic Cambisol) }\end{array}$ & $\begin{array}{c}\text { Flood-plain loam } \\
\text { (Eutric Fluvisol) }\end{array}$ & $\begin{array}{c}\text { Loam } \\
\text { (Haplic Phaeosem) }\end{array}$ \\
\hline Clay content $<2 \mu \mathrm{m}^{\mathrm{z}}$ & 4.6 & 24.9 & 14.4 \\
Silt content $2-20 \mu \mathrm{m}^{\mathrm{z}}$ & 4.1 & 8.9 & 15.2 \\
Fine sand content $20-200 \mu \mathrm{m}^{\mathrm{z}}$ & 52.0 & 40.3 & 65.3 \\
${\text { Coarse sand content } 200-2000 \mu \mathrm{m}^{\mathrm{z}}}^{\text {Particle density }}$ & 39.3 & 26.0 & 5.2 \\
Bulk density $^{\mathrm{y}}$ & 2.6 & 2.6 & 2.6 \\
Total carbon content $^{\mathrm{z}}$ & 1.6 & 1.3 & 1.4 \\
Field capacity $^{\mathrm{x}}$ & 0.7 & 1.5 & 1.4 \\
Permanent wilting point $^{\mathrm{x}}$ & 22.2 & 37.3 & 32.2 \\
\hline
\end{tabular}

${ }^{2}$ Percent by relative proportion of mineralic and organic matter.

Table 2. Treatments, target values of irrigation strategy, amount and frequency of water supply.

\begin{tabular}{lcc}
\hline $\begin{array}{l}\text { Irrigation } \\
\text { treatment }\end{array}$ & $\begin{array}{c}\text { Target value of irrigation } \\
(\% \text { vol ASW })\end{array}$ & $\begin{array}{c}\text { Amount applied per watering } \\
(\mathrm{mm})\end{array}$ \\
\hline 1 & 75 & 14 \\
2 & 55 & 14 \\
3 & 55 & $28^{\mathrm{y}}$ \\
4 & 35 & 14 \\
5 & 35 & $28^{\mathrm{y}}$ \\
6 & 35 & $42^{\mathrm{x}}$ \\
\hline
\end{tabular}


sides and bottom to protect against acropital and lateral water movement. Drainage tubes were used to remove excess water. Each plot was filled with a $0.25 \mathrm{~m}$ layer of gravel-sandy soil, then covered with either $0.50 \mathrm{~m}$ diluvial sand (Gleyic Cambisol), flood-plain loam (Eutric Fluvisol) or loessal loam (Haplic Phaeosem) (Table 1).

In 1995, the broccoli cultivar 'Emperor', is grown in U.S., ( $F_{1}$ hybrid, medium compact, early season, and widely cultivated cultivar, Sakata Seed Co.) was sown in a greenhouse on 15 Mar. for spring production. Plants were sown in artificial media, transplanted on 27 Apr. into sand and flood-plain loam soils (only) and harvested on 27 June. Broccoli for fall production was sown on 4 July, transplanted on 27 July and harvested on 29 Sept. Based on standard production practices, plants were spaced $0.50 \mathrm{~m}$ between rows and $0.40 \mathrm{~m}$ between plants in the row. Plants were off-set in adjacent rows, so that the plants were not directly opposite each other.

Plots were harvested twice, with an interval of three to five days, as in commercial practice. Nitrogen (N) fertilizer was applied with splittiming to produce a total $\mathrm{N}$ supply of 320 to $350 \mathrm{~kg} \cdot \mathrm{ha}^{-1}$ (sum of soil mineral $\mathrm{N}$ at a depth of 0 to $45 \mathrm{~cm}$ at planting, and the amount of $\mathrm{N}$ fertilizer added) in accordance with recommendations of the N-Expert model (Fink and Scharpf, 1993).

To determine broccoli response to a range of low, medium and high soil moisture regimes, three doses of water application were arranged at different soil moisture levels (Table 2). The plots were irrigated using a rail-bound self-moving lateral nozzle irrigation machine that delivered the required amount of water at a steady rate.

The soil moisture (volumetric water content) was manual recorded (two or more times per week in spring and daily (except on weekends) in fall by time domain reflectometry (TDR) probes (Easy Test Ltd, Poland). For each treatment, two probes were placed vertically at a depth of $0.20 \mathrm{~m}$ so that the wave guide/ resolution was beyond $5 \mathrm{~cm}$ in either direction of the transmission line. After measurements of soil moisture were made, the available soil water (ASW) was calculated by using the parameter of field capacity and wilting point. The mean values of both probes were used to determine when to irrigate. Another probe was placed at a depth of $0.40 \mathrm{~m}$ to record the moisture movement down through the soil, but was not used to predict the timing of the irrigation strategies.

In the period between planting (when the plants were at the three-leaf stage) and the start of the irrigation treatments, equal soil moisture levels ( $65 \%$ to $75 \%$ volASW) were established by irrigation in doses of 7 and $14 \mathrm{~mm}$. The plots were protected from rainfall by movable roofs covered with polyethylene transparent film and controlled by a rain sensor in connection with an electronic unit and electric motors. The plants were covered by the roofs only during periods of rain and, therefore, the effect of the roofs on light reduction and microclimate are assumed to be minimal.
Irrigation treatments began (when the plants were at the six-leaf stage) 19 and $12 \mathrm{~d}$ after the spring and fall plantings, respectively. Irrigation was applied whenever the soil moisture vol content decreased to the threshold values of available soil moisture $(75 \%, 55 \%$, and $35 \%$ ASW) (Table 2). The experiment was arranged with 12 plots for each treatment and two replications for each of the three soil types. The two replications were used for estimating total plant mass and head mass, and the best 12 plants, which consisted of $67 \%$ of the total plants per treatment of each replication, were used for the calculation. This was required in order to eliminate plants without heads, early heading, and the loss of single plants.

A two-way analysis of variance (ANOVA) with interaction was conducted using the STATISTICA program(StatSoft Inc., Tulsa, Okla.). Differences among treatments with the same level of ASW but different water doses (treatment two to treatment three and treatment four to treatment five to treatment six), and the same level water doses but different level of ASW (treatment one to treatment two to treatment four and treatment three to treatment five) were compared by the Tukey's honest significantdifference test (HSD). A significance level of $P=0.05$ was used.

\section{Results and Discussion}

Soilmoisture. Time course of measured soil moisture at a depth of $20 \mathrm{~cm}$ are shown in Fig. 1 for the sandy soil in spring, and in Fig. 2 for the flood-plain loam in fall. Calculated values of probes positioned at a depth of $0.40 \mathrm{~m}$ indicate that at no time did ASW exceed $95 \%$ vol and that there was no period for water leaching (data not shown). The maximum density of broccoli roots was at a depth of 10 to $45 \mathrm{~cm}$.

In spring production, the soil moisture fell below the high threshold value of available soil moisture (treatment one, $75 \%$ vol ASW, dose $14 \mathrm{~mm}$ ) on the sandy soil twice due to high evapotranspiration. The mean potential evapotranspiration $\left(\mathrm{ET}_{\mathrm{o}}\right)$, measured by German weather bureau, agricultural service, was 2.9 $\mathrm{mm}$ per day with a maximum of $5.8 \mathrm{~mm} \cdot \mathrm{d}^{-1}$ for spring production, and $2.5 \mathrm{~mm} \cdot \mathrm{d}^{-1}$ with a maximum of $6.3 \mathrm{~mm} \cdot \mathrm{d}^{-1}$ for fall production. The different irrigation treatments caused a temporal distribution of the cumulative water supply. Our results, based on the mean value of three soil types and two growing seasons, showed that $370 \mathrm{~mm}$ of water were applied for treatment one, $260 \mathrm{~mm}$ for treatment two, and $200 \mathrm{~mm}$ for treatment three. The differences between treatments two and three could be due to the higher watering frequency in treatment two and the greater unproductive evaporation.

\section{Yield}

Spring. The harvest length of the broccoli heads was $17 \mathrm{~cm}$. Analysis of variance showed that irrigation strategy significantly affected total and head mass per plant $(P<$ $0.05)$. The total mass per plant increased from $1087 \mathrm{~g}$ (treatment six, Table 3) to $1739 \mathrm{~g}$ on the sandy soil (treatment one), and from 1293 $\mathrm{g}$ (treatment four) to $1689 \mathrm{~g}$ on the flood-plain loam (treatment one, Table 3). Moreover, there
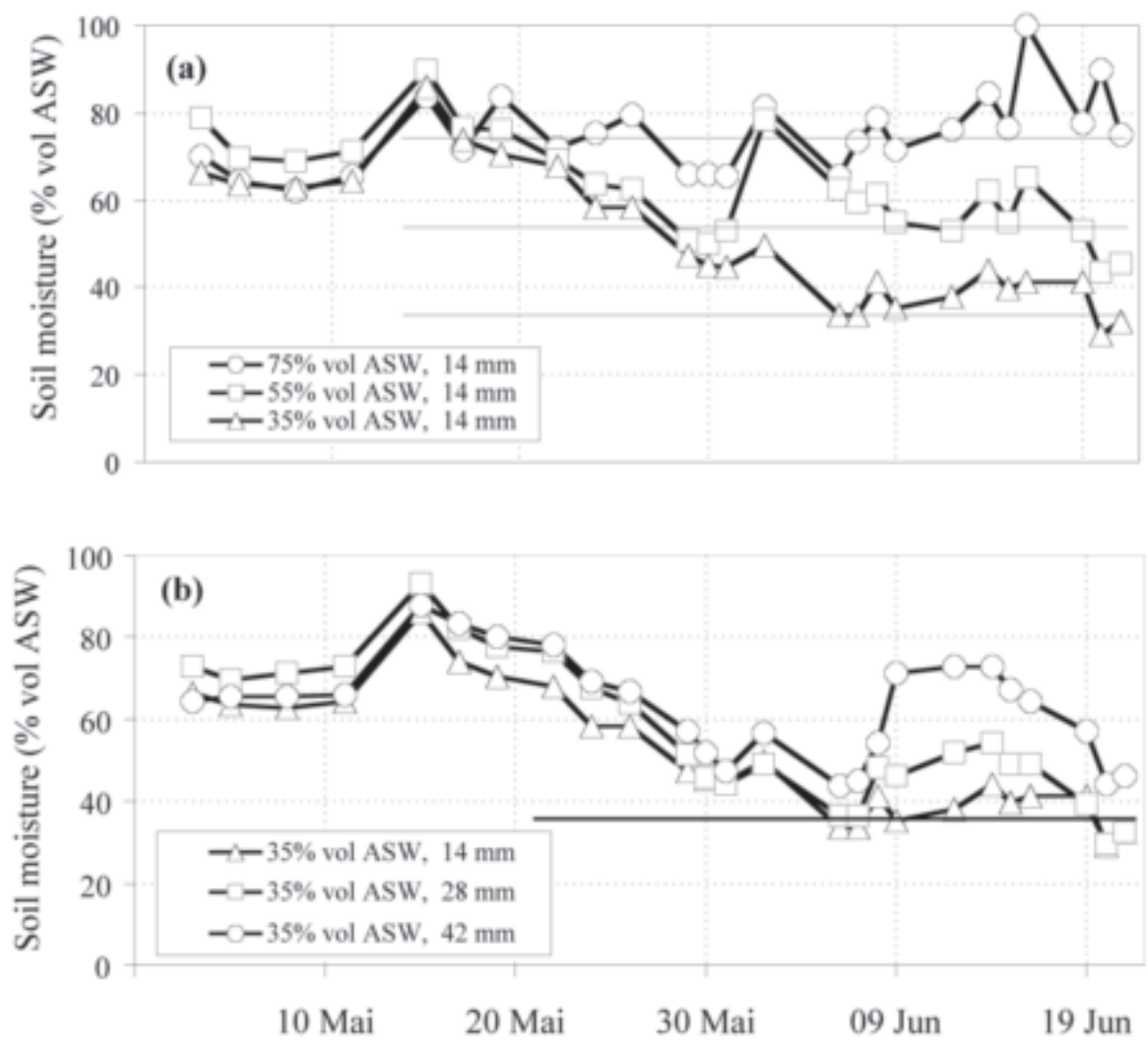

Fig. 1. Time course of soil moisture at a depth of $0.20 \mathrm{~m}$ on the sandy soil based on irrigation strategies during spring production for target values of (a) $75 \%$ vol available soil water (ASW), $55 \%$ vol ASW and $35 \%$ vol ASW, $14 \mathrm{~mm}$ of water applied, and target values of (b) $35 \%$ vol ASW, 14, 28, and 42 $\mathrm{mm}$ of water applied. 

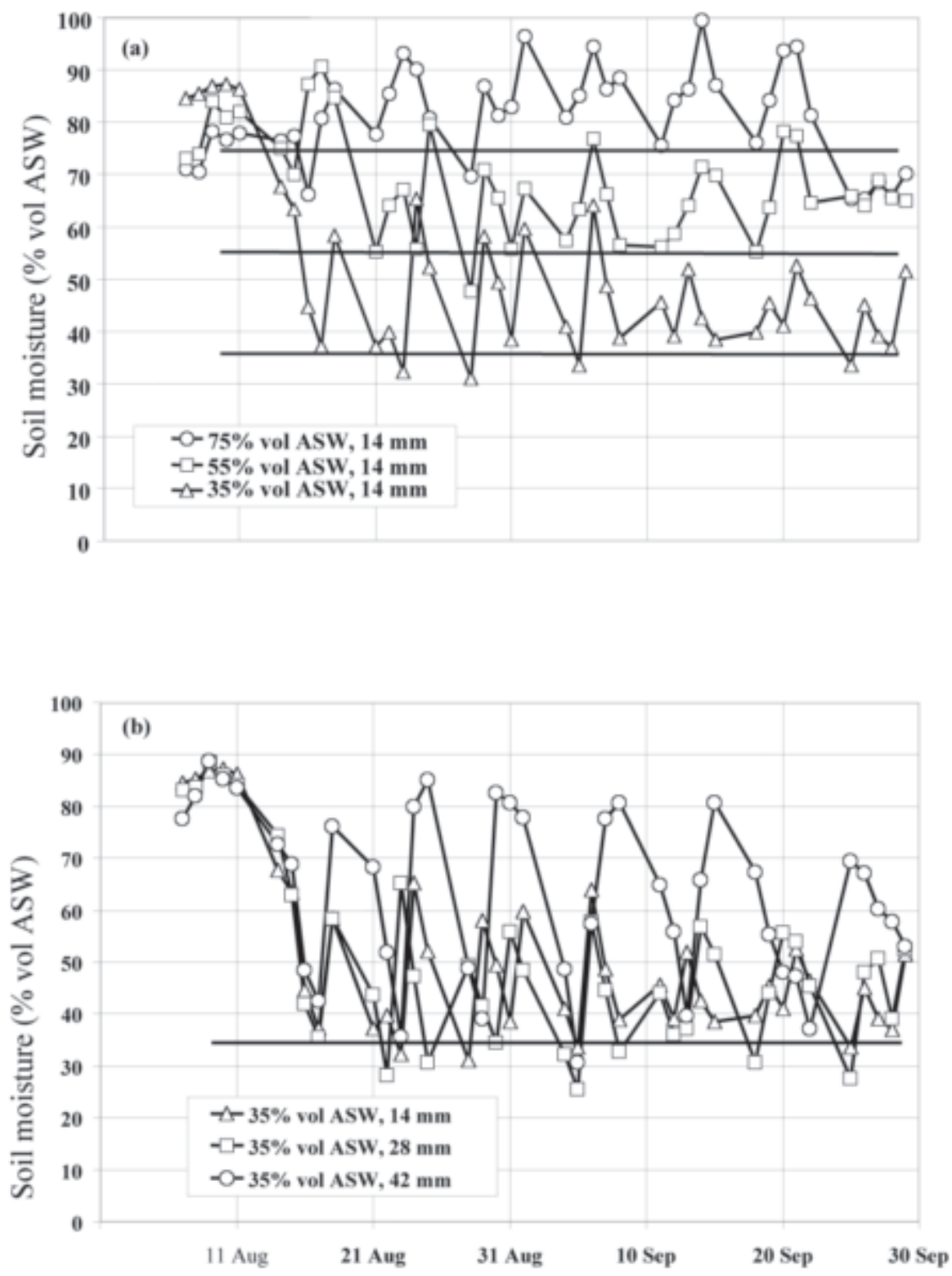

Fig. 2. Time course of soil moisture at a depth of $0.20 \mathrm{~m}$ on the flood-plain loam soil based on irrigation strategies during fall production for target values of (a) $75 \%$ vol available soil water (ASW), $55 \%$ vol ASW and 35\% vol ASW, $14 \mathrm{~mm}$ of water applied, and target values of (b) 35\% vol ASW, 14, 28, and $42 \mathrm{~mm}$ of water applied.

was a significant interaction between irrigation strategy and soil type only for total mass per plant. The highest mass per plant were obtained on the sandy soil.

Marketable head mass per plant was sig- nificantly affected by both irrigation strategy and soil type. The highest head mass per plant was observed in plants grown on the sand and flood-plain loam (510 g and $430 \mathrm{~g}$, respectively) under treatment two irrigation.
The mean head plant mass with treatment two was significantly higher compared to treatment four, but not significant compared to treatment one (Fig. 3, applied water $14 \mathrm{~mm}$ ).

The increase in the quantity of irrigated water applied with treatment two and treatment three (Fig. 3, applied water $14 \mathrm{~mm}$ twice, respectively) did not significantly increase head mass per plant. Plant head mass produced by treatment four was significantly lower than those produced by treatment two. Head mass with treatment five was significantly higher than that with treatment six but not significantly different to treatment four irrigation (Fig. 3). There were no irrigation strategy by soil type interactions for total plant mass or marketable head mass.

Fall. The fall production of broccoli yielded higher total plant and head mass than did spring production. Lower potential evapotranspiration $\left(2.5 \mathrm{~mm} \cdot \mathrm{d}^{-1}\right)$ and a 9-d longer growth period may have contributed to increased total and head mass of plants with treatments three to six (Table 3). Alonger duration of soil moisture above $75 \%$ vol ASW after irrigation reduced the growth of broccoli plants in treatment one in the sand (head mass, only) by reduced soil aeration. Only soil type had a marked effect on total mass per plant, and the lowest total plant mass was measured in plants grown in the loamy soil (Table 4).

In fall production, the greatest plant mass occurred in the sandy and flood-plain soils with treatment three, and the loam soil with treatment two (Tables 3 and 4). The lowest total plant mass with the sandy soil and flood-plain loam were 1931 and $2117 \mathrm{~g}$, respectively, with treatment one, and $1703 \mathrm{~g}$ with treatment four on the loam soil. There were no significant irrigation strategy $\times$ soil type interactions for total and head mass.

The marketable head mass per plant for the sand and flood-plain loam was only significantly affected by reduced soil moisture in the spring production (Fig. 3). Broccoli production in fall did not show significant differences in plant head mass (Fig. 4).

In the fall production, we did not find main or interactive effects of irrigation strategy and soil type for head mass. Soil moisture had no effect on the total mass of plants subjected to $55 \%$ vol ASW.

The comparatively lower potential evapotranspiration of $2.5 \mathrm{~mm} \cdot \mathrm{d}^{-1}$ in fall versus 2.9 $\mathrm{mm} \cdot \mathrm{d}^{-1}$ in spring did not lead to water stress in plants in any of the treatments. The low

Table 3. Effect of irrigation strategy, soil type and season on total- and head mass per plant of broccoli.

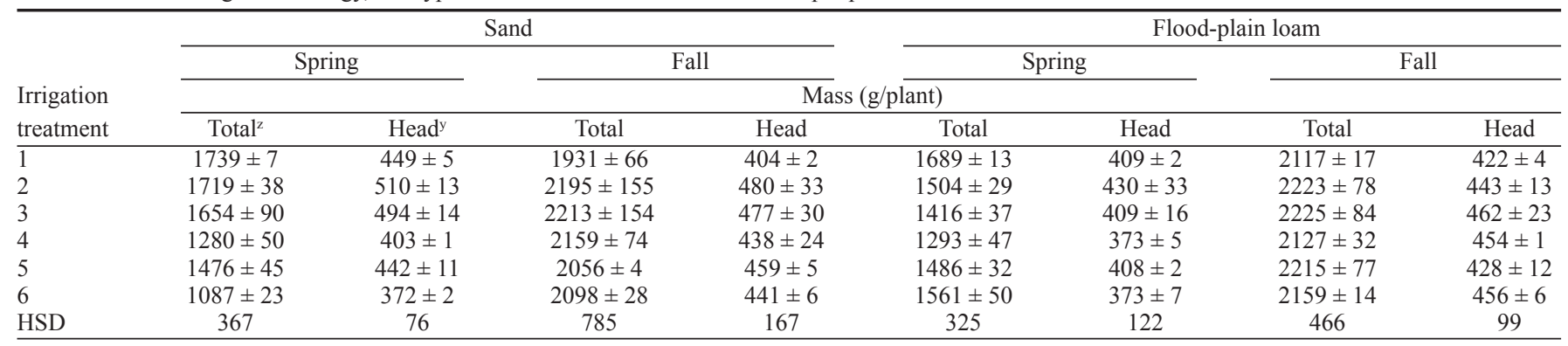

${ }^{2}$ Total mass $=$ mean total mass of 12 plants \pm standard error.

${ }^{\mathrm{y}} \mathrm{Head}$ mass $=$ mean head mass of $12 \pm$ standard error. 


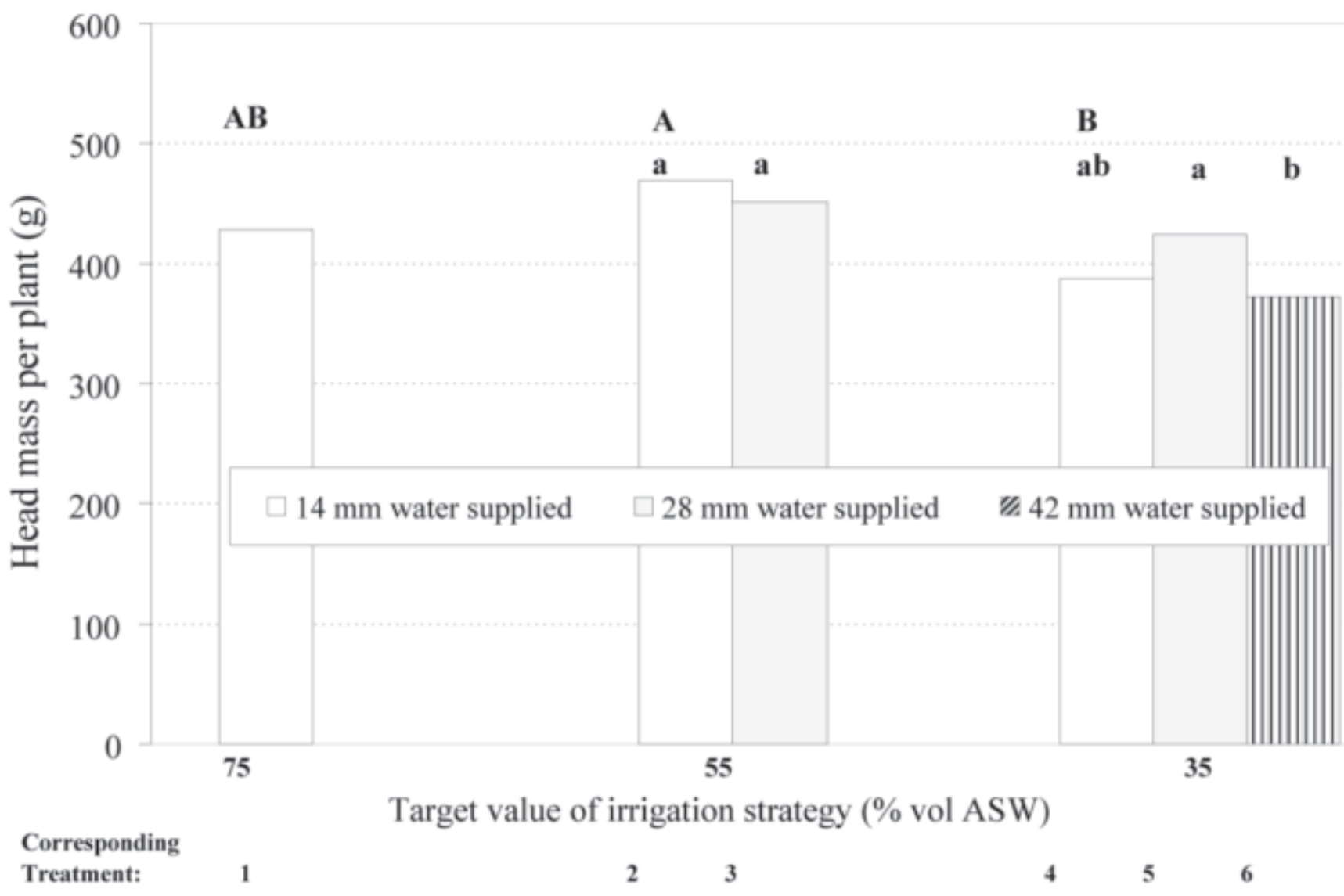

Fig. 3. Effect of soil moisture level and quantity of water supply on the head mass of plant in spring production on the sandy and flood-plain loam soil. Capital letters signify bars with difference at $14 \mathrm{~mm}$ irrigation applications and small letters signify differencce at 28 and $42 \mathrm{~mm}$ irrigation applications.

Table 4. Effect of irrigation strategy and season in the loam soil on broccoli total and head mass per plant.

\begin{tabular}{lcc}
\hline \multirow{2}{*}{$\begin{array}{l}\text { Irrigation } \\
\text { treatment }\end{array}$} & \multicolumn{2}{c}{ Fall } \\
\cline { 2 - 3 } & \multicolumn{2}{c}{ Mass (g/plant) } \\
\cline { 2 - 3 } Total $^{\mathrm{z}}$ & Head $^{\mathrm{y}}$ \\
2 & $2024 \pm 15$ & $408 \pm 17$ \\
3 & $2140 \pm 145$ & $446 \pm 36$ \\
4 & $1703 \pm 53$ & $445 \pm 17$ \\
5 & $1725 \pm 57$ & $401 \pm 10$ \\
6 & $1722 \pm 21$ & $384 \pm 14$ \\
HSD & 609 & 158 \\
\hline
\end{tabular}

${ }_{\mathrm{z}}$ Total mass $=$ mean total mass of 12 plants \pm standard error.

${ }^{y}$ Head mass $=$ mean head mass of 12 plants \pm standard error.

head mass per plant in treatment one could be due to the high soil moisture preventing maintenance of an adequate oxygen supply to the roots (Wiebe, 1981). Sanchez et al. (1994, 1996) also found that higher amounts of water (>430 $\mathrm{mm}$ applied water) reduced marketable yield in broccoli.

In fall production, soil moisture levels and irrigation intensities (treatments 1 to 6 ) had no significant effect on the total or head mass per plant (Table 3, Fig. 5). Higher water amounts of approximately $200 \mathrm{~mm}$ (mean value of treatments 4 to 6 and all soil types in the fall cultivation) did not result in any increase in the total or head mass per plant. This agrees with the studies of Doorenbos et al. (1979), who suggested that the rate of water uptake by cruciferous crops (including broccoli) starts to decline when the available soil water has been depleted by about $35 \%$ vol ASW. Moreover, a water requirement of about $200 \mathrm{~mm}$ is equivalent to the sum of 195 mm evapotranspiration during fall production. According to Doorenbos et al. (1979), the maximum crop coefficient $\left(\mathrm{K}_{\mathrm{c}}\right)$ for crucifers (including broccoli and cauliflower, Brassica oleracea L. botrytis group) is 1.1 in relation to the reference evapotranspiration (ET). For 64 $\mathrm{d}$ cultivation time, we calculated mean value of $2.5 \mathrm{~mm}$ for $\mathrm{ET}_{0}, 1.1$ for $\mathrm{K}_{c}$, and a total water requirement of $176 \mathrm{~mm}$. Letey et al. (1983) reported that irrigation to replenish water loss through evapotranspiration provided higher yields and higher nitrogen use efficiency as compared to excessive irrigation. Thompson et al. (2002 a 2002b) found that quality parameters (head weight and diameter) were much more responsive to $\mathrm{N}$ rate than to soil water tension. Imtiyaz et al. (2000) recorded the highest mean marketable yield of broccoli at $80 \%$ of pan evaporation replenishment. Sanchez et al. (1994) reported that both water deficit and excess irrigation generally produced negative results for cabbage (Brassica oleracea L. capitata group) production. Yield was optimized when crops were irrigated by replacing the amount of water lost by evapotranspiration. Verhaeghe and van der Krogt (1993) estimated the field capacity at desired moisture conditions for vegetables, and noted that at levels below $60 \%$ vol field capacity, crops became totally damaged. Gutezeit (2000) showed, by non-destructive measurements on leek (Allium ampeloprasum L. porrum group), that leeks should also be irrigated at $\geq 55 \%$ vol ASW (mean value of 15 and $30 \mathrm{~cm}$ depth), when the aim was to maximize yield.

In spring production, the irrigation strategy and soil type had a marked effect on the head mass per plant. The effect of irrigation strategy on the total mass per plant was greatest when plants were grown in the sandy soil. The highest head mass per plant was observed in the sandy soil with treatment two in both spring and fall-grown broccoli.

\section{Conclusions}

The results of this experiment with 'Emperor' indicate that both the total and marketable head mass of broccoli are significantly influenced by the irrigation strategy, in spring production only. We could detect no significant head mass yield differences between the three soil types grown in fall.

The highest head mass was never found at the highest available soil water level, i.e., plants irrigated at $75 \%$ vol ASW. To reduce the risk of high plant mass but low head mass per plant, the soil moisture level and water supply should be adjusted to meet the water demand of the developing broccoli heads. It is recommended that irrigation be started when soil moisture falls below $50 \%$ vol ASW, followed by rewatering with an application rate 


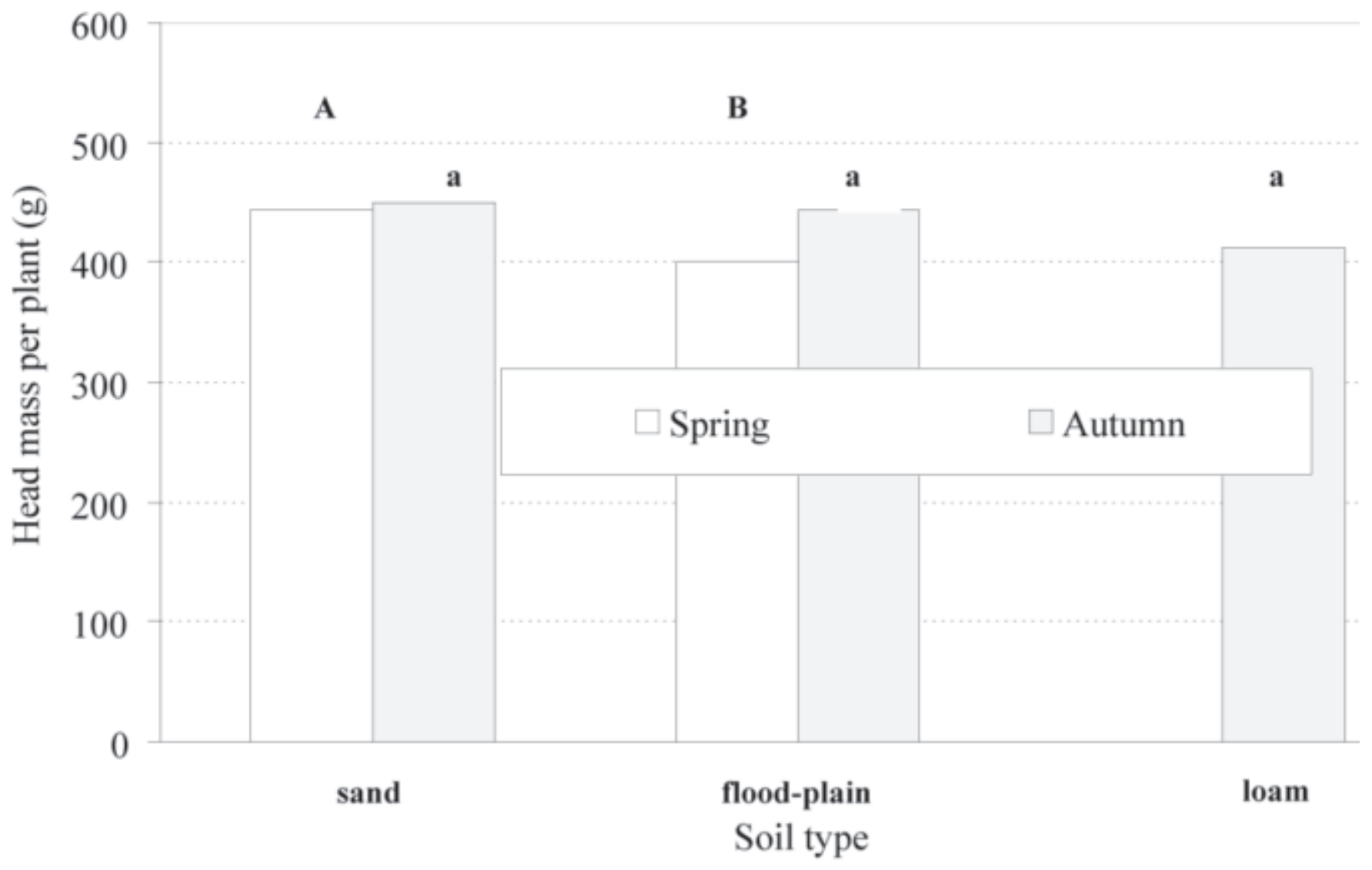

Fig. 4. Effect of soil type and harvest season time on the head mass of plants grown in the sandy-, flood-plain- and loam soils. Capital letters above respective bars denote significant differents in the spring harvest. The same small letters above bars indicate that there were no fall harvest differences.

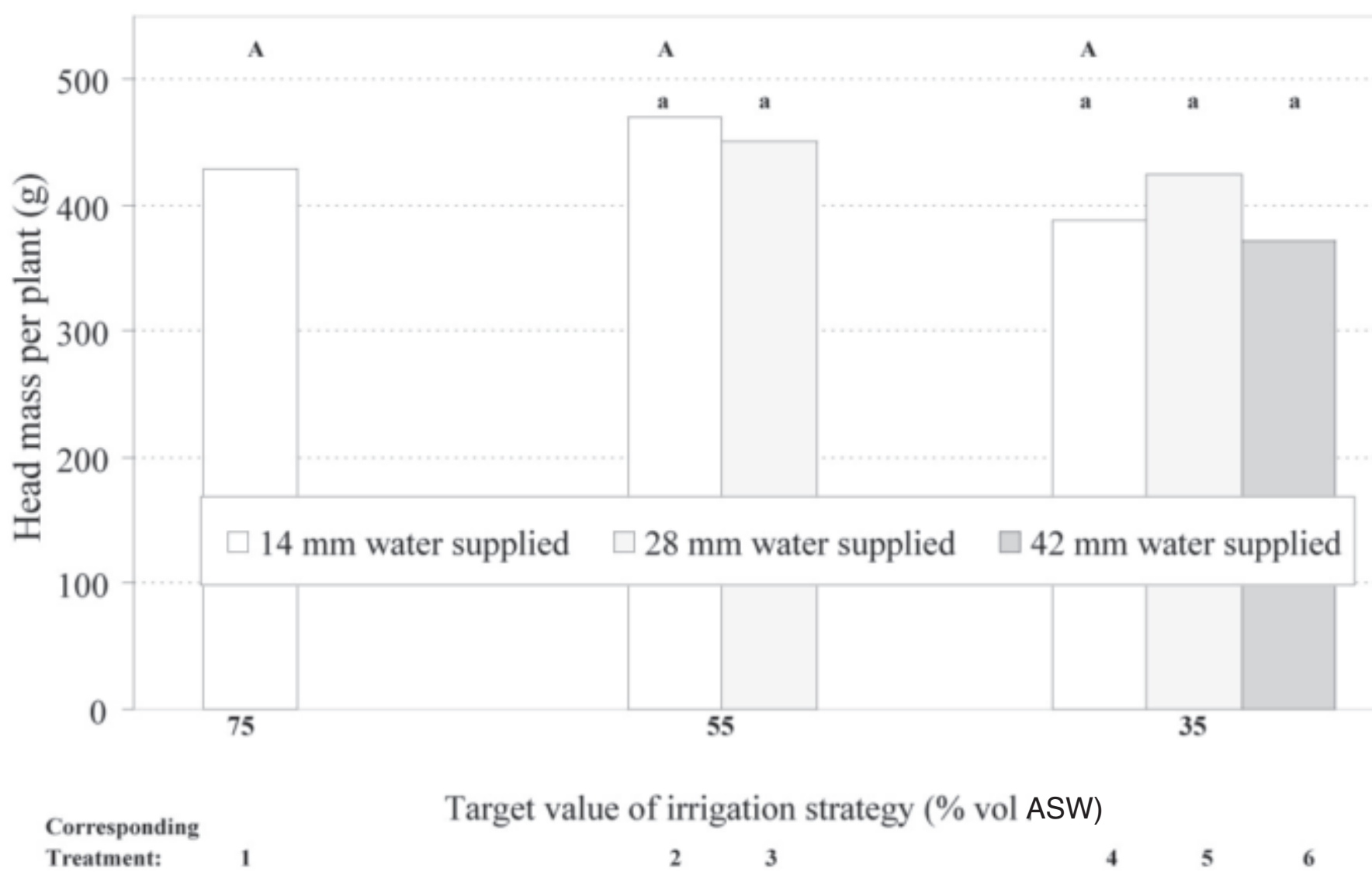

Fig. 5. Effect of the irrigation strategy on the head mass per plant of fall grown broccoli. Bars with the same capital or small letters are not significantly different. 
of 14 or $28 \mathrm{~mm}$. Total water amounts applied with the different rates (treatments four, five, and six) only differed by $12 \mathrm{~mm}$. This indicates that irrigation water mainly contributes to an increase in soil moisture and may be a result of low water interception of broccoli crops and water loss from the soil surface by evaporation in the developed canopy. When these recommendations are implemented, it is possible to produce highly marketable heads of broccoli, and also to reduce the amount of water supplied.

\section{Literature Cited}

Alvino, A., G. Barbieri, and E. Tarantino. 1990. Irrigation of vegetable crops in Italy, with special regard to the Basilicata Region. Acta Hort. 278:33-54.

Behr, H.C. 2001. ZMP-Bilanz Gemüse (Central market and price office for vegetable), Bonn, Germany.

Buchleiter, G.W. and R. Unruh. 1993. Managing center pivots with CAMIS and SCHED. Session II: Irrigation scheduling and design, p. 1-15. 15th Intl. Congress on Irrigation and Drainage, The Hague, The Netherlands.

Cavazza, L. 1988. Problems in irrigation at farm and yield levels. Acta Hort. 228:19-34.

Dasberg, S. and O. Dani. 1999. Drip irrigation. Springer-Verlag Berlin.

Doorenbos, J. andA.H. Kassam. 1979. Yield response to water. FAO Irr. Drainage Paper 33.

Fink, M. and H.C. Scharpf. 1993. N-Expert-Adecision support system for vegetable fertilization in the field. Acta Hort. 339:65-72.
Gutezeit, B., F.N. Herzog, and K.O. Wenkel. 1993. Irrigation scheduling computer program (Das Beregnungsbedarfssystem für Freilandgemüse). Gemüse 2:106-108.

Gutezeit, B. 2000. Using a non-destructive growth measurement technique to estimate the critical soil moisture level for leek. Acta Hort. 537:805-812.

Hsiao, T.C. 1990. Plant-atmosphere interactions, evapotranspiration, and irrigation scheduling. Acta Hort. 278:55-66.

Imtiyaz, M., N.P. Mgadla, S.K. Manase, K. Chendo, and E.O. Mothobi. 2000. Yield and econo-mic return of vegetable crops under variable irrigation. Irr. Sci. 19 (2):87-93.

Letey, J., W.M. Jarrel, N. Valoras, and R. Beverly. 1983. Fertilizer application and irrigation management of broccoli production and fertilizer use efficiency. Agron. J. 75:502-507.

Mannocchi, F. and P. Mecarelli. 1993. A soil-water-crop model for a large scale. Session III: Soil water flow and crop production under irrigation and drainage, p. 1. 15th Intl. Congress on Irrigation and Drainage, The Hague, The Netherlands.

Rana, A.G. and N. Katerji. 1998. A measurement based sensitivity analyses of the Penman-Monteith actual evapotranspiration model for crops of different height and in contrasting water status. Theor. Appl. Climatol. 60:141-149.

Sanchez, C.A., R.L. Roth, and B.R. Gardner. 1996. Economic responses of broccoli and cauliflower to water and nitrogen in the desert. HortScience 31:201-205.

Sanchez, C.A., R.L. Roth, and B.R. Gardner. 1994. Irrigation and nitrogen management for sprinkler-irrigated cabbage on sand. J. Amer. Soc. Hort. Sci. 119:427-433.
Sharda, V.N. and S.R. Singh. 1993. A finite model for simulation of soil moisture balance during plant growth. Session III: Soil water flow and crop production under irrigation and drainage. p. 1-24. 15th Intl. Congress on Irrigation and Drainage, The Hague, The Netherlands.

Smith, R.E. 1993. Simulation of crop water balance with Opus. Session III: Soil water flow and crop production under irrigation and drainage, p. 16. 15th Intl. Congress on Irrigation and Drainage, The Hague, The Netherlands.

Teixeira, J.L., R.M. Fernando, and L.S. Pereira. 1993. Relreg, a model for real time irrigation and scheduling. Session II: Irrigation scheduling and design, p. 1-15. 15th Intl. Congress on Irrigation and Drainage, The Hague, The Netherlands.

Thompson, T.L., T.A. Doerge, and R.E. Godin. 2002a. Subsurface drip irrigation and fertigation of broccoli: II. Agronomic, economic, and environmental outcomes. Soil Sci. Soc. Amer. J. 66(1):178-185.

Thompson, T.L., T.A. Doerge, and R.E. Godin. 2002b. Subsurface drip irrigation and fertigation of broccoli: I. Yield, quality, and nitrogen uptake. Soil Sci. Soc. Amer. J. 66(1):186-192.

Ventura, F., B.A. Faber, K.M. Bali, R.L. Snyder, D. Spano, P. Duce, and K.F. Schulbach. 2001. Model for estimating evaporation and transpiration from row crops. J. Irr. Drainage Eng. (Nov-Dec.):339-345.

Verhaeghe R.J. and W.N.M. Van der Krogt. 1993. Crop water modelling with an operational management perspective, p. 1-15. 15th Intl Congress of Irrigation and Drainage, The Hague, The Netherlands.

Wiebe, H.J. 1981. Effect of water quantity on physiological disorders and quality of plants. Acta Hort. 119:67-76. 